\section{In praise of Holt as head of the AAAS}

The American Association for the Advancement of Science (AAAS) has chosen Rush Holt, who was a Democratic congressman for eight terms, as its new chief executive. Daniel Sarewitz attacks this choice as "political" (Nature 516, 9; 2014), but it is not partisan.

The AAAS announcement praises Holt for broadly promoting "the value of science communication, particularly for conveying information about climate change". In its March 2014 Climate Science Panel report, the AAAS talked bluntly about the dangers of inaction and of poor science communication - a view you share in calling on scientists to ensure that "they are not bested in the court of public opinion" (Nature 464, 141; 2010).

Sarewitz contends that the AAAS is "anointing a leader who could take up the fight" with climate-science deniers, among whom are many Republican politicians. But in Holt, the AAAS has a scientist who understands the fight that we are in (see also Nature 471, 265-266; 2011) and is well placed to defend it from attacks by Congress. He is an inspired choice.

Joseph Romm Center for American Progress, Washington DC, USA. jromm@americanprogress.org

\section{Shale gas: nuance in output predictions}

You claim that the most recent estimates of future output for shale gas in the United States have become more conservative, but in our view this is a red herring (Nature 516, 28-30; 2014).

State-of-the-art projections for the world's future shale-gas supplies hinge on improved quantification of the uncertainty range and reducing its spread (called 'de-risking' a shale play) as experience and technology advance. Several of the studies you quote include uncertainty ranges that explain the current spread in forward projections of future US gas supplies. That crucial nuance was missing from your graphic, however, which shows only a simplified, discrete forward-production prognosis.

Comparing just one scenario from the study by the team at the University of Texas at Austin with another from the US Energy Information Administration's shale-gas outlook, omitting uncertainty ranges, creates an apparent mismatch where one may not in fact exist.

As a result of technology innovation (see also Nature 516, $7 ; 2014$ ), the United States is today drilling 3-kilometre-long horizontal wells and conducting 30-stage fracture treatments at depths of $3.7 \mathrm{~km}$. Further technological gains will increase global oil and gas output (see, for example, S. Neff and M. Coleman Energy Strategy Rev. 5, 6-13; 2014). Oil and gas prices also drive global shale development.

No one can accurately predict both the technology improvement rate and future wellhead prices, so we have to rely on a range of forecasts based on a variety of assumptions.

Steve Holditch, Dan Hill, Ruud Weijermars Texas A\&M University, College Station, USA. r.weijermars@pe.tamu.edu

\section{Shale gas: hardly a fallacy}

We believe that your comparison of US fracking forecasts creates a false dichotomy between modelling results from the US Energy Information Administration (EIA) and the Bureau of Economic Geology at the University of Texas at Austin (Nature 516, 28-30; 2014).

Our integrated team of scientists, engineers and economists at the University of Texas has built rigorous models that incorporate a wide range of input variables and wellconstrained outcome scenarios. In our view, the comparison of just one simulation run with a single outlook from the EIA trivializes a complex problem and fails to represent accurately the rigour and uniqueness of what is being accomplished in our fouryear study (see go.nature.com/ zfverj).

Your graphic 'Battle of the forecasts' is partially attributed to our data. Although we present preliminary results at conferences and make them available on our website, we explained to the author that our work on the Haynesville and Marcellus plays was not yet finished or published, and requested that it should not be used. We therefore question why you should choose to base the main thread of your argument on a comparison to our unfinished work

Finally, I find your headline 'The fracking fallacy' potentially misleading: in isolation, it reads as a negative comment on the fracking process itself, rather than on forecasts of natural gas production. Production of US oil is currently at a 30-year high, and of natural gas at an all-time high. Hydraulically fractured wells account for more than half and almost half, respectively, of US natural gas and oil production. To imply otherwise does a disservice to your readers.

Scott W. Tinker, Svetlana Ikonnikova The University of Texas at Austin, Texas, USA. scott.tinker@beg.utexas.edu

Editorial note: Scott Tinker and Svetlana Ikonnikova informed Nature that their study was unpublished. They subsequently made the data publicly available, at which point Nature used that information and gave appropriate credit.

\section{United Nations highlights soil crisis}

Some 500 years after Leonardo da Vinci declared that more was known about celestial bodies than about the soil underfoot, the United Nations has proclaimed
2015 the International Year of Soils. This offers a unique opportunity to address the crisis in soil sustainability (see www. fao.org/soils-2015).

Among the factors undermining soil quality are intensive farming, industrial activity and increasing urbanization. Soil contamination is threatening food production, water potability and ecosystem services, notably in large parts of China. Safeguarding soils is therefore crucial to the UN Post2015 Development Agenda and the Sustainable Development Goals (go.nature.com/s7jcik).

Initiatives that are already under way for the sustainable management of complex soil systems include the Intergovernmental Technical Panel on Soils, the Global Soil Biodiversity Initiative, the Global Network of Critical Zone Observatories, and the International Soil Modeling Consortium.

Henry Lin Institute of Earth Environment, Chinese Academy of Sciences, Xian, China; and Pennsylvania State University, University Park, USA.

Rainer Horn Christian Albrechts University zu Kiel, Germany. henrylin@psu.edu

\section{CORRECTIONS}

The 'West Asia' article in the Nature Index (Nature 515, S88S89; 2014) stated that King Abdullah University of Science and Technology had an article count of 121 and a weighted fractional count of 9.96. In fact, it was King Abdulaziz University that had these values.

In the Nature Index China, the 'Chinese Academy of Sciences' article (Nature 516, S56-S57; 2014) should have affiliated Peng Zhang to the Institute of Plant Physiology and Ecology. And in the 'Beijing' article (Nature 516, S60-S61; 2014), Ning Jiao's quote was mistranslated, so it has been updated. 